\title{
Significant Alterations of Serum Cytokine Levels in Patients with Peyronie's Disease
}

\author{
Reinhold P. Zimmermann, Gerhard Feil, Conny Bock, Lorenz Hoeltl, Arnulf Stenzl
}

Department of Urology (RPZ, LH), Elisabethinen Hospital, University Affiliated Hospital, Universities of Vienna and Innsbruck, Linz, Austria, and Department of Urology (GF, CB, AS), Eberhard-KarlsUniversity of Tuebingen, Tuebingen, Germany

\begin{abstract}
Objective: To determine the expression of the cytokines transforming growth factor- $\beta 1$ (TGF- $\beta 1$ ), interferon- $\gamma$ (IFN- $\gamma$ ), interleukin-6 (IL-6), and tumor necrosis factor- $\alpha$ (TNF- $\alpha$ ) in serum from patients with Peyronie's disease (PD) compared to healthy controls.

Materials and Methods: Ninety-one consecutive PD patients aged 20 - 74 years were included in this study. All patients were diagnosed with symptomatic PD for the first time and had a palpable penile plaque. The patients previously had the disease for 6 - 72 months. None of the patients had a severe infectious disease or known systemic illness. For cytokine analyses, peripheral venous blood samples were obtained before treatment. Fifty healthy male blood donors aged 22 - 64 years served as the control group. TGF- $\beta 1$, IFN- $\gamma$, Il-6, and TNF- $\alpha$ were analyzed quantitatively with commercial immunoassays.

Results: Mean cytokine levels in serum from patients were increased for TGF- $\beta 1$ and IFN- $\gamma$ compared to healthy controls. The difference for TGF- $\beta 1$ was considered statistically significant $(p<0.001)$. IL-6 was not detectable in PD patients ( $p$ $<0.01)$ and TNF- $\alpha$ was decreased $(\mathrm{p}<0.0001)$.

Conclusion: The significantly elevated serum level of the profibrotic TGF- $\beta 1$ cytokine underscores the effect of cytokines in the pathophysiology of PD. The significantly decreased TNF- $\alpha$ serum level suggested no acute immunomodulatory process. Therefore, the relevance for therapeutic administration of TNF- $\alpha$ should be further investigated. Quantification of TGF- $\beta 1$ in serum of PD patients provides a possible diagnostic tool and target for therapy. The data on altered cytokine levels in PD patients also provide a new understanding for etiopathogenesis of PD, which warrants further investigation.
\end{abstract}

Key words: Peyronie's disease; pathophysiology; cytokines; IL-6; TNF- $\alpha$; TGF- $\beta$; IFN- $\gamma$

Int Braz J Urol. 2008; 34: 457-66

\section{INTRODUCTION}

Peyronie's disease (PD) has been known for a very long time and even the ancient Egyptians reported PD-like symptoms. In 1743, the French surgeon and court physician François de la Peyronie was the first to scientifically describe penile deviation due to tumors and penile nodes (1). He separated the syndrome from more common sexually transmitted diseases. PD was previously thought to be associated with unnatural or excessive sexual behavior. Degenerative alterations like ageing of the penile fascia layers or penile trauma were considered as possible causes of PD as well as systemic diseases like hyperuricemia, diabetes, rheumatism, and regular alcohol or nicotine consumption. PD is thought to mainly affect $0.15-3.0 \%$ of men between the age of 40 - 60 years. The origin of the superficial fibromata with plaque formation between 
the corpora cavernosa and the tunica albuginea (TA) still remains unknown $(2,3)$.

The anatomical-pathological correlation of PD might be a traumatically caused inflammation followed by proliferation of fibroblasts and the formation of scar areas such as fibrous plaques and, in some cases, bone formation. The indurations are primarily found on the dorsal surface of the penis and can extend as far as the corpora cavernosa and the deep penile fascia. Smith, in his histological investigations, explained that $\mathrm{PD}$ was a form of fibrosis resulting from chronic vasculitis (2). The hypothesis that penile micro-traumata and disorders resulting from the healing of wounds can cause PD has been reported as the most likely explanation (4).

The involvement of the immune system in triggering fibroblast proliferation or an autoimmune reaction to infectious agents, as well as an alteration in the collagen metabolism, have been reported as possibilities due to the fact that erectile tissue in $\mathrm{PD}$ patients exhibits a significant increase of collagen fibers (5-7).

Consistently due to the important role of cytokines in mediating inflammation and fibrosis, the identification of appropriate mediators could lead to a better understanding of pathophysiological mechanisms in PD. Accordingly, inflammatory cytokines like IL- 6 and TNF- $\alpha$ and the fibrosis-associated cytokines TGF- $\beta$ and IFN- $\gamma$ are of particular interest. TGF- $\beta$ is known to induce fibrosis and IFN- $\gamma$ is a marker for fibroblast proliferation.

\section{MATERIALS AND METHODS}

Ninety-one consecutive patients initially diagnosed with symptomatic PD were included in this study. Age range of the patients was $20-74$ (average age 52) years. All patients had a palpable penile plaque, which was verified by means of magnet resonance tomography (MRT) (detection rate 100\%). The plaques led to penile deviation during erection in all patients, $70 \%$ of these showed a deviation angle between $30-60$ degrees. The patients previously had the disease for at least 6 months (range $6-72$ months). None of the patients had a severe infectious disease or known systemic illness. All patients were intended to be treated by extracorporeal shock wave therapy (ESWT) in the context of a prospective randomized placebo controlled study. All additional treatment procedures were stopped at least 12 weeks prior to inclusion in the study. For cytokine analyses, peripheral venous blood samples were obtained before treatment. Fifty healthy male blood donors aged 22 - 64 (average age 41) years with no systemic or local disease served as a control group. Serum samples were immediately stored at $-20^{\circ} \mathrm{C}$ and defrosted for cytokine determination at regular intervals. Cytokine levels were determined quantitatively by commercially available immunoassays (Table-1). Cytokines were measured in duplicates. The assays were performed according to the manufacturer's instructions. Statistical analyses were calculated by t-test using JMP software for personal computers (Version 3.2.6., SAS Institute Inc., Cary, NC)

\section{RESULTS}

Analyses of the fibrosis-associated cytokines TGF- $\beta 1$ and IFN- $\gamma$ revealed increased levels in serum from patients compared to healthy male blood donors. TGF- $\beta 1$ was increased by $14 \%$, whereas IFN- $\gamma$ was not expressed in the healthy controls (Figures- 1 and

Table 1 - Immunoassays used for cytokine detection.

\begin{tabular}{lc}
\hline Parameter & Method \\
\hline TGF- $\beta 1$ & Immunoassay (R\&D-Systems Inc., Minneapolis, MN.) \\
INF- $\gamma$ & Immunoassay (R\&D-Systems Inc., Minneapolis, MN.) \\
IL-6 & Immulite-System (DPC, Los Angeles, CA.) \\
TNF- $\alpha$ & Immulite-System (DPC, Los Angeles, CA.) \\
\hline
\end{tabular}


$2)$. The difference for TGF- $\beta 1$ was statistically highly significant $(\mathrm{p}<0.001)$. The inflammatory cytokine IL-6 was not detectable in PD patients (Figure-3).
Interestingly, TNF- $\alpha$ was 5 -fold higher in serum of healthy blood donors (Figure-4). Differences in comparison to the control group were statistically

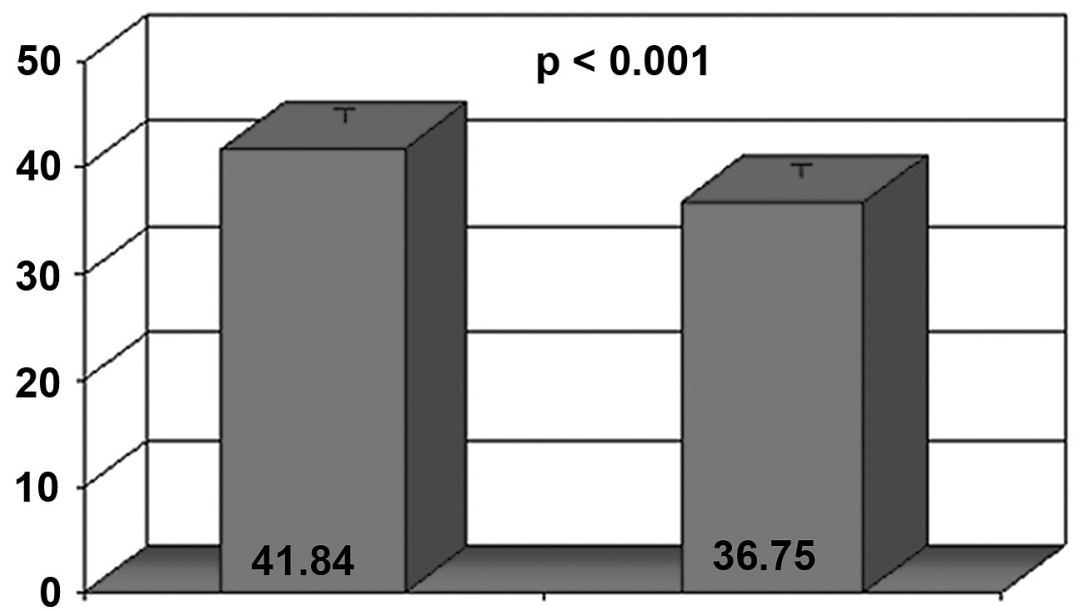

Patients

Blood donors

\section{TGF- $\beta 1(\mathrm{ng} / \mathrm{mL})$}

Figure 1 - TGF- $\beta 1$ serum levels in PD patients and healthy blood donors.

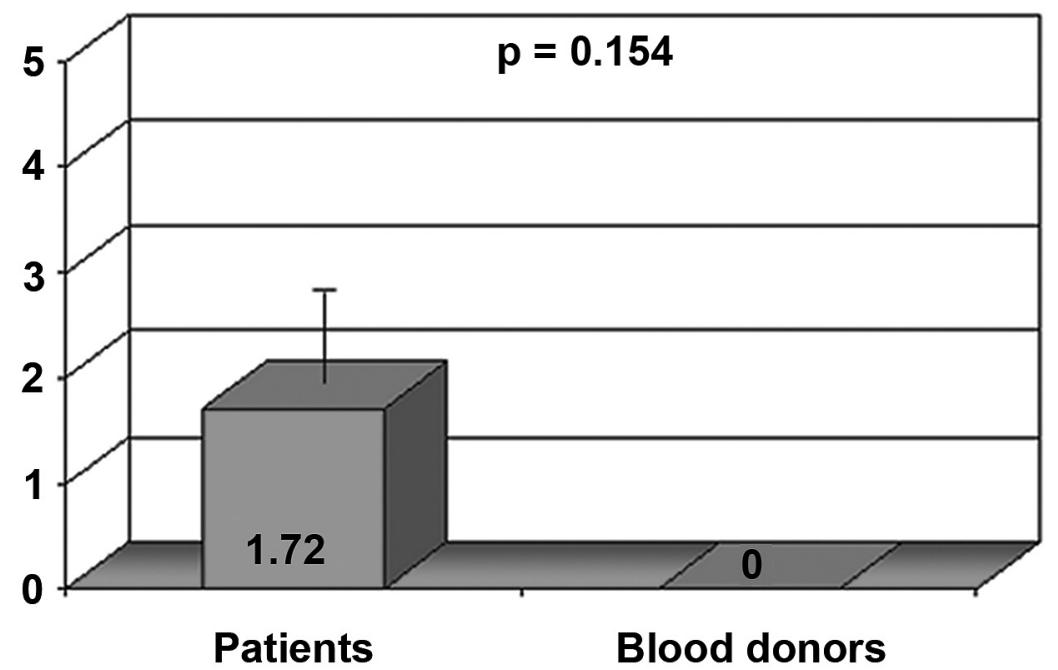

IFN-g $(p g / m L)$

Figure $2-I F N-\gamma$ serum levels in PD patients and healthy blood donors. 


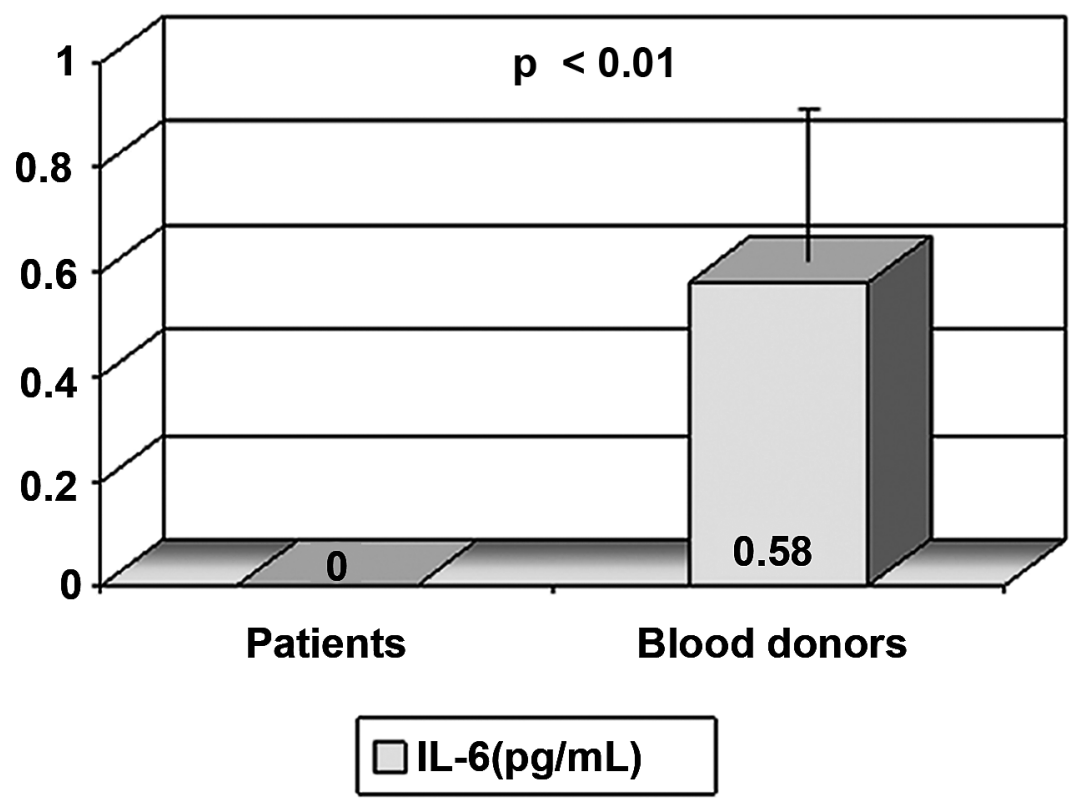

Figure 3 - IL-6 serum levels in PD patients and healthy blood donors.

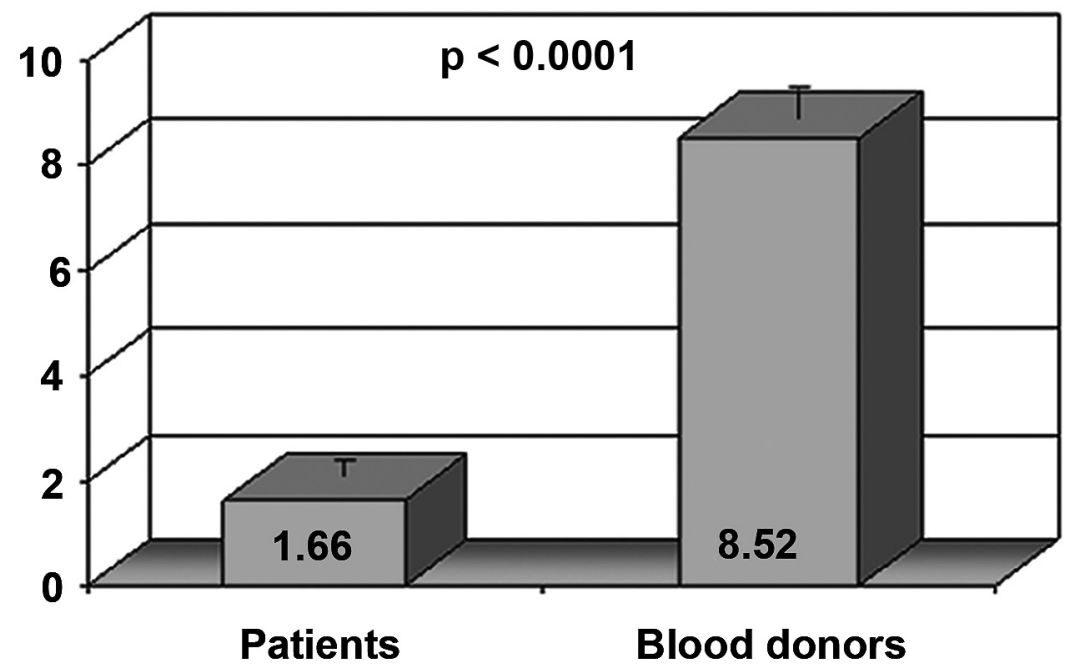

TNF-a $(p g / m L)$

Figure $4-T N F-\alpha$ serum levels in PD patients and healthy blood donors.

significant for IL-6 $(\mathrm{p}<0.01)$ and highly significant for TNF- $\alpha(p<0.0001)$. The mean values $( \pm$ SEM $)$ and ranges of TGF- $\beta 1$, IFN- $\gamma$, IL- 6 , and TNF- $\alpha$ are shown in Table- 2 . 
Table 2 - Mean values ( \pm SEM, standard error of the mean) and range of cytokine levels in serum of PD patients and male blood donors.

\begin{tabular}{lccccc}
\hline \multirow{2}{*}{ Parameter } & \multicolumn{2}{c}{ Patients $(\mathrm{N}=91)$} & \multicolumn{2}{c}{ Blood Donors $(\mathrm{N}=50)$} & \\
& $\begin{array}{c}\text { Mean Value } \\
( \pm \mathrm{SEM})\end{array}$ & Range & $\begin{array}{c}\text { Mean Value } \\
( \pm \mathrm{SEM})\end{array}$ & Range & p Value \\
\hline $\mathrm{TGF}-\beta 1(\mathrm{ng} / \mathrm{mL})$ & $41.84( \pm 1.15)$ & $21.70-61.80$ & $36.75( \pm 0.72)$ & $27.31-51.39$ & $<0.0002$ \\
$\mathrm{IFN}-\gamma(\mathrm{pg} / \mathrm{mL})$ & $1.72( \pm 0.89)$ & $0.00-63.75$ & $0.00( \pm 0.00)$ & & 0.1540 \\
$\mathrm{IL}-6(\mathrm{pg} / \mathrm{mL})$ & $0.00( \pm 0.00)$ & & $0.58( \pm 0.29)$ & $0.00-8.90$ & 0.0068 \\
$\mathrm{TNF}-\alpha(\mathrm{pg} / \mathrm{mL})$ & $1.66( \pm 0.31)$ & $0.0-18.20$ & $8.52( \pm 0.56)$ & $0.00-20.5$ & $<0.0001$ \\
\hline
\end{tabular}

\section{COMMENTS}

Cytokines promote communication between immunocompetent cells. Thus, if illness activates the immune system, cytokine levels are locally or - despite a short half life - systemically measurable. Previous investigations have opened a possible link between various types of cytokines and PD provoking factors.

All patients with $\mathrm{PD}$ over a long period of time, i.e. at least more than 12 months, who were scheduled to be treated within our placebo-controlled prospectively randomized ESWT study, had to meet the strict inclusion criteria. The patients who previously had undergone different medical therapy schedules without exception, had their therapy stopped at least three months before treatment and therefore also prior to cytokine investigation. The majority had been treated by vitamin E or para-aminobenzoic acid. However, at the beginning of our investigation no patients were allowed to undergo any additional therapy either pharmacological or physical. Due to the extremely varying treatment schemes, it made no sense in our opinion to stratify the patients with regards to duration or type of previous treatments. In fact, patient's medical history continued the same course in the vast majority of cases for more than 12 months. This was established by the fact that the "stable disease" was one of the crucial inclusion criteria for our prospectively randomized ESWT study.

Subdividing the patients based on age did not seem reasonable because the particular length of PD medical history was a crucial factor for this study. Therefore, we could not explain why, for example, a patient at the age of 30 with PD for a certain period of time showed different results from a patient of 60 with PD.

However, the majority of our patients were between 40 to 60 years of age.

Cytokines levels after ESWT, to our knowledge, have not been previously investigated. This is regrettable from the current point of view and at the time the ESWT study was completed we did not know the results of the cytokines investigation. Therefore, we did not conclude that it could be of interest to repeat the investigations after the end of ESWT treatment.

The major profibrotic cytokines are IL-4, TGF- $\beta 1$ and platelet derived growth factor, while IL- 6 and TNF- $\alpha$ can act as potent promoters of inflammatory and destructive processes in fibrotic diseases. In contrast, IFN- $\gamma$ is known as the most potent antifibrotic agent. This was the rational basis for making this choice of cytokines.

Fibrosis is a pathologic process including scar formation and overproduction of extracellular 
matrix by connective tissue as a response to tissue damage. It involves inflammation and disruption of normal tissue architecture followed by tissue repair and accumulation of mesenchymal cells. The molecular process is not different from normal formation of connective tissue and extracellular matrix in organs. Pathogenesis of fibrosis has not yet been completely understood. Evidence has been accumulating which suggests that immunologically and cytokine mediated mechanisms are pivotal.

Cytokines may have a causal connection with fibrotic diseases, leading to typical and final alterations of organs and their functionality. They are well known to be involved in many fibrotic diseases
(Table-3) of lung, liver, kidney, pancreas, and systemic aggressive fibromatosis as well as colloid and hypertrophic scar formation (8-13). With the exception of a reported series from our group including a smaller patient population (14) to our knowledge there have been no further investigations of serum cytokine levels in PD.

TGF- $\beta$ can be considered as an immunoregulatory and strong profibrotic factor, which is antagonized in part by IFN- $\alpha$. and $-\gamma$. The wound healing process in TA in particular involves TGF- $\beta 1$, showing a clear correlation to other fibrotic diseases. Pulmonary or liver fibrosis also show elevated local expression of fibrotic factors causing alterations in

Table 3 - Local and systemic cytokine alterations in various fibrosis-associated diseases.

\begin{tabular}{|c|c|c|c|c|}
\hline Disease & $\begin{array}{l}\text { TGF-beta-1 } \\
\text { (profibrotic) }\end{array}$ & $\begin{array}{l}\text { IFN-gamma } \\
\text { (anti TGF-b1) }\end{array}$ & $\begin{array}{c}\text { IL-6 } \\
\text { (fibrogenic) }\end{array}$ & $\begin{array}{l}\text { TNF-alpha } \\
\text { (mitogenic) }\end{array}$ \\
\hline Peyronie's disease & $+(\mathrm{S}) /+(\mathrm{l})$ & $+(\mathrm{S})$ & $-(\mathrm{S})$ & $-(\mathrm{S})$ \\
\hline Cystic fibrosis (mild disease) & $+(\mathrm{L})$ & $+(\mathrm{L})$ & & \\
\hline Cystic fibrosis (acute phase) & $-(\mathrm{L})$ & $-(\mathrm{L})$ & & $-(\mathrm{L}) /(\mathrm{S})$ \\
\hline Cystic fibrosis (chronic phase) & $+(\mathrm{L})$ & $-(\mathrm{L})$ & $+(\mathrm{L})$ & $+(\mathrm{L})$ \\
\hline Bronchiolitis obliterans & & $+(\mathrm{L})$ & $+(\mathrm{L})$ & \\
\hline Pulmonary fibrosis (chronic) & $+(\mathrm{L})$ & & $+(\mathrm{L})$ (transplant patients) & \\
\hline Chronic obstructive pulmonary disease & $+(\mathrm{L})$ & & $+(\mathrm{L})$ & $+(\mathrm{L})$ \\
\hline Pulmonary fibrosis (idiopathic) & $+(\mathrm{L})$ & & & $+(\mathrm{L})$ \\
\hline Hepatitis viral acute & No change & & $+(\mathrm{S})$ & $+(\mathrm{S})$ \\
\hline Hepatitis viral chronic/cirrhosis & $+(\mathrm{S})$ & $-(\mathrm{S})$ & $+(\mathrm{S})$ & $+(\mathrm{S})$ \\
\hline $\begin{array}{l}\text { Hepatitis C } \\
\text { (recurrent following lung transplantation) }\end{array}$ & $+(\mathrm{S})$ & & & \\
\hline Liver fibrosis chronic & & & & $+(\mathrm{S})$ \\
\hline Pancreatitis chronic (onset) & & $+(\mathrm{L})$ & $+(\mathrm{L})$ & $+(\mathrm{L})$ \\
\hline Aggressive fibromatosis & $+(\mathrm{L})$ & & $+(\mathrm{L})$ & $+(\mathrm{L})$ \\
\hline $\begin{array}{l}\text { Peritonitis chronic in peritoneal dialysis } \\
\text { patients }\end{array}$ & $-(\mathrm{L})$ & & $-(\mathrm{L})$ & \\
\hline Oral submucosis fibrosis & & $-(\mathrm{S})$ & $+(\mathrm{S})$ & $+(\mathrm{S})$ \\
\hline Hypertrophic scar tissue & $+(\mathrm{S})$ & & & \\
\hline
\end{tabular}

$+=$ increased level; - = decreased level; $L=$ local alterations (tissue); $S=$ alterations in peripheral blood. 
the composition of connective tissue. For example, patients who had peritonitis during continuous ambulatory peritoneal dialysis showed increased levels of TGF- $\beta 1$ in the peritoneal dialysate effluent in relation to non-infectious patients, which has been considered as an active release of these proinflammatory cytokines (15).

Idiopathic pulmonary fibrosis, the adult respiratory distress syndrome, and the focal tumor stroma in lung cancer have also revealed a local increase of TGF- $\beta 1$ (9). Serum concentrations of TNF- $\alpha$ and TGF- $\beta 1$ have shown to be significantly increased in the majority of patients with chronic viral hepatitis and liver cirrhosis (8). In severely wounded patients elevated serum levels of TGF- $\beta 1$ have been reported. These authors concluded that this could be due to secretion of wound fibroblasts (16). In the development of renal fibrosis, TGF- $\beta 1$ is considered to play a key role as regards cytokines and growth factors (10). In contrast, in an animal model the progression of chronic liver fibrosis could have been prevented by inhibition of TGF- $\beta 1$ (17). In a major series conducted by Hauck and co-workers it was shown that genetic alterations of the TGF- $\beta 1$ gene could influence the predisposition to PD (18). In the rat penis of a PD animal model (19), as well as in TA of PD patients, local TGF- $\beta 1$-expression was reported to be 5-fold higher than in healthy subjects. Injections of TGF- $\beta 1$ or the very similar cytomodulin in TA of rat penis produced chronic cellular infiltration, elastosis, thickening, and clumping of collagen bundles. These PD-like histological alterations resulted in a significant reduction of erectile function $(20,21)$. Incision and suture repair of the rat penis revealed inflammatory reactions similar to those observed in an acute phase of PD, in particular a transient up-regulation of TGF- $\beta 1$ protein expression. Thus, TGF- $\beta 1$ has been clearly shown to be an initiation factor of wound healing as well as fibrosis. Possibly, the transformation of the inactive TGF- $\beta 1$ molecule into an active one is already induced even by minimal tissue lesions with consecutive cellular reparative and fibrotic mechanisms. This fact supports the theory of a traumatic genesis of PD. Based on these findings TGF- $\beta 1$ may be considered to be one of the central agents in the predisposition and manifestation of PD.
Additionally, other plaque-inducing substances like fibrin (22) might be involved. The significantly higher TGF- $\beta 1$ levels in serum of PD patients revealed major systemic factors of well known local alterations, particularly as none of the patients showed further signs of fibrotic alterations, but revealed the "typical" pro-fibrotic cytokine constellation in serum. Our results significantly demonstrated a critical role for TGF- $\beta 1$ in the formation of PD and suggest that anti-TGF- $\beta 1$ intervention might have a therapeutic effect on fibrotic penile tissue, not only by suppressing fibrosis but also by facilitating regeneration of TA cells.

IL-6 is a multifunctional cytokine and acts as the main synthesis mediator for many acute phase proteins involved in proinflammatoric and cytotoxic conditions. Acute phase proteins may also contribute to the regulation of fibrosis by inhibition of proteases and by binding of cytokines. IL-6 serum levels were increased in the acute inflammation phase of viral hepatitis (23) and in the airways of patients with chronic fibrosis (CF) $(24,25)$. Tissue mRNA expression of IL-6 in patients not only with acute but also with chronic viral hepatitis, was slightly elevated $(8,23)$. In a rat model for chronic pancreatitis IL-6 tissue expression was able to be established (11). IL-6 gene polymorphism led to an increased number of chronic fibrotic lung diseases in transplanted patients (26). In addition, patients with peritoneal dialysis related chronic peritonitis exhibited increased levels of IL-6 in the peritoneal dialysate effluent (15). In contrast, it has been demonstrated in our previously reported investigation that the acute-phase proteins alpha-1-antitrypsin and alpha-2-macroglobulin were not detectable in serum of patients with PD (14). In this study, IL- 6 could not be demonstrated in serum of PD patients. Therefore, acute immunological defense mechanisms do not appear to play any particular role in PD. This has been confirmed by the finding that other systemic indicators of acute inflammation like CRP (C-related protein) were only slightly increased in serum of PD patients (14).

TNF- $\alpha$ influences the production of collagenase and fibroblast growth. Local expression of TNF- $\alpha$ occurs in many acute and chronic fibrotic diseases (27-29). TNF- $\alpha$ promotes the course of these diseases and is considered to influence both 
the damage and the repair process by regulating additional mediators. Immunological processes or initial perivasculitis might explain the involvement of TNF- $\alpha$ in the etiology of PD. In animals with artificial cochlear inflammation TNF- $\alpha$ induced an amplification of the immune response leading to an increase of inflammation and disease progression (28). In patients with acute exacerbation of cystic fibrosis, the secretion of TNF- $\alpha$ was significantly lower in comparison with healthy controls and returned to normal secretion after treatment $(24,25,30)$. In the airways of $\mathrm{CF}$ patients significantly elevated levels of circulating proinflammatory cytokines, in particular TNF- $\alpha$ have been reported (24). Other pulmonary diseases harboring diffuse fibrotic alterations like idiopathic pulmonary fibrosis, adult respiratory distress syndrome, lung cancer and chronic pancreatitis have revealed elevated TNF- $\alpha$ levels $(9,11)$. In serum of patients with severe chronic hepatitis and liver cirrhosis significantly higher TNF- $\alpha$ levels were found compared to healthy controls, whereas patients with mild chronic hepatitis did not exhibit such alterations. In our study, serum TNF- $\alpha$ levels were significantly decreased. This finding does not indicate a systemic involvement of TNF- $\alpha$ in etiopathogenesis of PD. In general, TNF- $\alpha$ seems to be involved in acute and highly active phases of fibrotic diseases. The majority of patients included in our study had a duration of PD longer than 12 months. The decreased TNF- $\alpha$ levels found in our study therefore may possibly be an indicator for the chronic phase of PD in our patients (stable disease). Due to these low TNF- $\alpha$-levels, it could be concluded that an anti-fibrotic therapy of PD based on TNF- $\alpha$ does not appear to be promising.

IFN- $\gamma$ can reduce collagen synthesis, proliferation of fibroblasts with subsequent fibrotic activity and increase collagenase production. In the airway epithelium of CF patients increased levels of IFN- $\gamma$ mRNA should be verified (30). The mRNA of both IFN- $\gamma$ and IL- 6 mRNA were elevated for liver specimens of a transgenic mouse model for chronic hepatitis $\mathrm{C}$-virus liver disease. In spontaneous chronic pancreatitis in a rat model, IFN- $\gamma$ was related to the progression of chronic pancreatitis (11). These findings are in agreement with the significantly increased IFN- $\gamma$ serum levels detected in our series of PD patients.
Anti-TGF- $\beta 1$ agents have been considered to be a therapeutic option in various fibrotic diseases $(31,32)$. The basis of that assumption is a down regulation of the fibrotic protein expression induced by IFN- $\gamma$. On the one hand, our results may explain that therapeutically administered local IFN- $\gamma$ was seen to be ineffective as PD plaques barely responded to local interferon therapy. On the other hand, elevated IFN- $\gamma$ levels in PD patients might be a type of physiological defense mechanism as in antifibrotic activities.

\section{CONCLUSION}

No straightforward description of the pathophysiological process that leads to the formation of PD is currently known. To our knowledge, the present study is the first reported series with special emphasis on fibrogenic factors in patient's serum.

Cytokines, in particular TGF- $\beta 1$ and IFN- $\gamma$ play a local and systemic role in the formation of PD. Local or systemic cytokine patterns might be crucial in different stages of PD. Micro traumata in the tunica albuginea could be the triggering incident.

TGF- $\beta 1$ may be a target for an antifibrotic PD therapy as well as the first marker for PD therapy response. TGF- $\beta 1$ serum levels should be integrated in future therapy studies. The role of cytokines in PD, in particular TGF- $\beta 1$, should be followed-up in clinical as well as in investigative trials.

\section{ACKNOWLEDGEMENT}

Drs. Reinhold P. Zimmermann and Gerhard Feil have both contributed equally to this work.

\section{CONFLICT OF INTEREST}

The authors have nothing to disclose.

\section{REFERENCES}

1. Nöske HD, Hauck EW: Morbus Lapeyronie aus historischer Sicht. Aktuel Urol. 2001; 32 (Suppl 1): 2-6. 
2. Smith BH: Peyronie's disease. Am J Clin Pathol. 1966; 45: 670-8.

3. Smith BH: Subclinical Peyronie's disease. Am J Clin Pathol. 1969; 52: 385-90.

4. Devine CJ Jr, Somers KD, Jordan SG, Schlossberg SM: Proposal: trauma as the cause of the Peyronie's lesion. J Urol. 1997; 157: 285-90.

5. Leffell MS: Is there an immunogenetic basis for Peyronie's disease? J Urol. 1997; 157: 295-7.

6. Bichler KH, Lahme S, Mattauch W, Petri E: Collagen metabolism in induratio penis plastica (IPP). Urologe A. 1998; 37: 306-11.

7. Somers KD, Sismour EN, Wright GL Jr, Devine CJ Jr, Gilbert DA, Horton CE: Isolation and characterization of collagen in Peyronie's disease. J Urol. 1989; 141: 629-31.

8. Mammaev SN, Lukina EA, Shul'pekova IuO, Levina AA, Ivashkin VT: Cytokine regulation of liver inflammation and fibrosis during chronic hepatic diseases. Klin Lab Diagn. 2001; 12: 37-40.

9. Martinet $Y$, Menard $O$, Vaillant $P$, Vignaud $P$, Vignaut JM, Martinet N: Cytokines in human lung fibrosis. Arch Toxicol Suppl. 1996; 18: 127-39.

10. Eddy AA: Molecular basis of renal fibrosis. Pediatr Nephrol. 2000; 15: 290-301.

11. Xie MJ, Motoo Y, Su SB, Sawabu N: Expression of tumor necrosis factor-alpha, interleukin-6, and interferon-gamma in spontaneous chronic pancreatitis in the WBN/Kob rat. Pancreas. 2001; 22: 400-8.

12. Haque MF, Meghji S, Khitab U, Harris M: Oral submucous fibrosis patients have altered levels of cytokine production. J Oral Pathol Med. 2000; 29: 123-8.

13. Mills BG, Frausto A, Brien E: Cytokines associated with the pathophysiology of aggressive fibromatosis. J Orthop Res. 2000; 18: 655-62.

14. Feil G, Bichler KH, Lahme S, Götz T: Investigations on cytokines in serum of patients with Peyronie's disease. Akt Urol. 2001; 32 (Suppl 1): 33-6.

15. Lai KN, Lai KB, Lam CW, Chan TM, Li FK, Leung JC: Changes of cytokine profiles during peritonitis in patients on continuous ambulatory peritoneal dialysis. Am J Kidney Dis. 2000; 35: 644-52.

16. Tredget EE, Wang R, Shen Q, Scott PG, Ghahary A: Transforming growth factor-beta mRNA and protein in hypertrophic scar tissues and fibroblasts: antagonism by IFN-alpha and IFN-gamma in vitro and in vivo. $\mathrm{J}$ Interferon Cytokine Res. 2000; 20: 143-51.

17. Nakamura T, Sakata R, Ueno T, Sata M, Ueno H: Inhibition of transforming growth factor beta prevents progression of liver fibrosis and enhances hepatocyte regeneration in dimethylnitrosamine-treated rats. Hepatology. 2000; 32: 247-55.

18. Hauck EW, Hauptmann A, Schmelz HU, Bein G, Weidner W, Hackstein H: Prospective analysis of single nucleotide polymorphisms of the transforming growth factor beta-1 gene in Peyronie's disease. J Urol. 2003; 169: 369-72.

19. Lin CS, Lin G, Wang Z, Maddah SA, Lue TF: Upregulation of monocyte chemoattractant protein 1 and effects of transforming growth factor-beta 1 in Peyronie's disease.Biochem Biophys Res Commun. 2002; 295: 1014-9.

20. El-Sakka AI, Hassoba HM, Chui RM, Bhatnagar RS, Dahiya R, Lue TF: An animal model of Peyronie's-like condition associated with an increase of transforming growth factor beta mRNA and protein expression. J Urol. 1997; 158: 2284-90.

21. Bivalacqua TJ, Diner EK, Novak TE, Vohra Y, Sikka SC, Champion HC, et al.: A rat model of Peyronie's disease associated with a decrease in erectile activity and an increase in inducible nitric oxide synthase protein expression. J Urol. 2000; 163: 1992-8.

22. Davila HH, Ferrini MG, Rajfer J, Gonzalez-Cadavid NF: Fibrin as an inducer of fibrosis in the tunica albuginea of the rat: a new animal model of Peyronie's disease. BJU Int. 2003; 91: 830-8.

23. Missale G, Ferrari C, Fiaccadori F: Cytokine mediators in acute inflammation and chronic course of viral hepatitis. Ann Ital Med Int. 1995; 10: 14-8.

24. Bonfield TL, Konstan MW, Berger M: Altered respiratory epithelial cell cytokine production in cystic fibrosis. J Allergy Clin Immunol. 1999; 104: 72-8.

25. Osika E, Cavaillon JM, Chadelat K, Boule M, Fitting $\mathrm{C}$, Tournier G, et al.: Distinct sputum cytokine profiles in cystic fibrosis and other chronic inflammatory airway disease. Eur Respir J. 1999; 14: 339-46.

26. Lu KC, Jaramillo A, Lecha RL, Schuessler RB, Aloush A, Trulock EP, et al.: Interleukin-6 and interferongamma gene polymorphisms in the development of bronchiolitis obliterans syndrome after lung transplantation. Transplantation. 2002; 74: 1297-302.

27. Elborn JS, Norman D, Delamere FM, Shale DJ: In vitro tumor necrosis factor-alpha secretion by monocytes from patients with cystic fibrosis. Am J Respir Cell Mol Biol. 1992; 6: 207-11.

28. Satoh H, Firestein GS, Billings PB, Harris JP, Keithley EM: Tumor necrosis factor-alpha, an initiator, and etanercept, an inhibitor of cochlear inflammation. Laryngoscope. 2002; 112: 1627-34. Erratum in: Laryngoscope. 2003; 4: 291. 
29. Wang X, Chen YX, Xu CF, Zhao GN, Huang YX, Wang QL: Relationship between tumor necrosis factoralphaand liver fibrosis. World J Gastroenterol. 1998; 4: 18.

30. Wojnarowski C, Frischer T, Hofbauer E, Grabner C, Mosgoeller W, Eichler I, et al.: Cytokine expression in bronchial biopsies of cystic fibrosis patients with and without acute exacerbation. Eur Respir J. 1999; 14: 1136-44.
31. Oldroyd SD, Thomas GL, Gabbiani G, El Nahas AM: Interferon-gamma inhibits experimental renal fibrosis. Kidney Int. 1999; 56: 2116-27.

32. Takahara T, Sugiyama K, Zhang LP, Ando O, Fujii M, Yata Y, et al.: Cotreatment with interferon-alpha and -gamma reduces liver fibrosis in a rat model. Hepatol Res. 2004; 28: 146-154.
Accepted after revision: May 13, 2008

Correspondence address:

Dr. Gerhard Feil

Department of Urology

Eberhard-Karls-University of Tuebingen

Hoppe-Seyler-Str. 3

72076 Tuebingen, Germany

E-mail: gerhard.feil@med.uni-tuebingen.de

\section{EDITORIAL COMMENT}

Despite the prevalence of Peyronie's disease is increasing fast, until now we do not know the exact pathophysiological mechanism of this disease. The main hypothesis is an inflammatory reaction followed by fibroblasts proliferation and scar tissue formation. However, even this mechanism was not proven yet. So far, how and why fibrosis takes place is not clear. Anyway, cytokines and in particular TGF-beta seem to play a crucial role in Peyronie's disease. If it is so, any information about these very mediators is very welcome. Furthermore, until we do understand why and how fibrosis and Peyronie's disease occur we will not really treat the disease itself.
In our opinion, it is time to search the pathophysiological process that causes Peyronie's disease, in the same that the authors did in this valuable article. In the era that aggressive surgeries to manage Peyronie's disease are being reviewed, probably understanding inflammatory reaction and fibrogenic factors are way to go. In this way, I really believe that cytokines, mainly TGF-beta are the keys to understand what really happens in the tunica albuginea due to Peyronie's disease.

Only after knowing this mechanism, we would treat and cure the disease, instead of manage its complications with poor results.

Dr. Joaquim A. Claro Division of Urology University of Sao Paulo, USP Sao Paulo, Brazil E-mail:joaquimclaro@hotmail.com 